Sudan. The health conditions of civilian population in Juba became catastrophic due to lack of means and budget. They were facing problems such as:

1. Poor environment and inadequate water hygiene;

2. Poor nutritional status; and

3. Collapsed health service system

Against this situation, the ICRC continues to provide various activities in Juba:

1. Health care services;

2. Distribution of food and non-food items;

3. Tracing and reuniting of unaccompanied people;

4. Dissemination of International Humanitarian Law; and

5. Co-operation programme with the Sudanese Red Crescent Society.

As for medical services, the ICRC medical team aimed to assist local staff in surgical projects at the Juba Teaching Hospital (JTH). The JTH had 500 beds and 1,000 employees. Local doctors worked irregularly and were undependable. The medical assistants performed the actual medical practices. An ICRC surgeon performed 200 operations per month, mainly for infected wounds debridement and abscess drainage. The hospital received 34 war-wounded cases in six months.

Keywords: abscess; armed conflict; disaster relief; healthcare; ICRC; Juba Teaching Hospital; nutrition; Sudan; surgery; water; wounds Prehosp Disast Med 2002;17:s21-22.

\section{Ex-Post Evaluation of Japan Disaster Relief Assistance}

Koichi Sasadate, ${ }^{1}$ Masabiro Hashizume, ${ }^{2}$

Hisayoshi Kondo, ${ }^{3}$ Norimasa Seo; ${ }^{4}$ Tatsuo Ono: ${ }^{1}$

Katsunari Harada, ${ }^{1}$ Mitsutaka Hoshi; ${ }^{1}$ Takasbi Mizuno; ${ }^{1}$

Yukio Ishida, ${ }^{1}$ Yuji Okazaki ${ }^{1}$

1. Secretariat of Japan Disaster Relief Team, Japan International Cooperation Agency, Japan

2. Department of International Community Health, Graduate School of Medicine, University of Tokyo, Japan

3. Department of Emergency and Critical Care Medicine, Nippon Medical School, Japan

4. Department of Anesthesiology and Critical Care Medicine, Jichi Medical School, Japan

Objective: To observe and evaluate the activity of the Japan Disaster Relief Medical Team that was dispatched to Mozambique to assist during the great flood disaster in March, 2000 using "reduction of personnel damage (humanitarian relief)" perspective as the focus point.

Methods: The activity of the Japan Disaster Medical Team was evaluated using a survey according to the seven "rights": 1) right information; 2) right time; 3) right place; 4) right person; 5) right materials; 6) right coordination and cooperation; and 7) right technology.

Results: Effective data indicating the move of flood-attributed Internally Displaced Persons (IDPs) and disease trend were obtained and examined.

Conclusion: For the first time, the Japan International Cooperation Agency dispatched a post-disaster evaluation team. It concluded that such a retrospective evaluation is extremely useful for providing more effective and more efficient disaster relief activities by Japan.

Keywords: evaluation; flood; international disaster relief; JICA; seven rights

Prehosp Disast Med 2002;17:s22.

\section{Evaluation of Health Disaster Management During} the Mozambique Flood in $\mathbf{2 0 0 0}$

Hisayoshi Kondo, ${ }^{1}$ Norimasa Seo, ${ }^{2}$ Masabiro Hasbizume, ${ }^{3}$

Kouichi Sasadate, ${ }^{4}$ Yasubiro Yamamoto ${ }^{1}$

1. Department of Emergency and Critical Care Medicine, Nippon Medical School, Japan

2. Department of Anesthesiology and Critical Care Medicine, Jichi Medical School, Japan

3. Department of International Community Health, Graduate School of Medicine, University of Tokyo, Japan

4. Disaster Assistance Division, Japan International Cooperative Agency(JICA), Japan

Background: In 2000, a major flood occurred in the southern part of Mozambique. Hokwe in the Chokwe Province, Gaza State, was one of the most severely affected areas. A Japan Disaster Relief Medical Team was dispatched into this area to evaluate the health disaster management during this flood using the Guidelines for Evaluation and Research in the Utstein Style.

Methods: The Initial Health Disaster Severity Score developed by the Gothenburg working group was used to assess the health status in affected area. For the evaluation research of the response, the idea of Template $\mathrm{B}$ and $\mathrm{C}$ on the guideline was used.

Results: Average severity score of the disaster was 41.6. The high scores were seen in the category of Medical, Impact on health care system, and Preparedness. The needs in this disaster were confirmed by the use of evaluation research. Infectious diseases were prevalent, and local health system could not cope with it. Therefore, international cooperation activities toward were found to be fit these needs.

Conclusion: The Guidelines for Evaluation and Research in the Utstein Style could be used in the case of a slow onset national disaster.

Keywords: DHSS; evaluation, flood; infectious diseases; Utstein template

Prehosp Disast Med 2002;17:s22.

\section{Evaluation of the Activities of the Japan Disaster Relief (JDR) Medical Team for Flood Relief in} Mozambique

Norimasa Seo, ${ }^{1}$ Hisayoshi Kondo, ${ }^{2}$ Masabiro Hashizume, ${ }^{3}$

Kouichi Sasadate; ${ }^{4}$ Yasubiro Yamamoto ${ }^{2}$

1. Department of Anesthesiology and Critical Care Medicine, Jichi Medical School

2. Department of Emergency and Critical Care Medicine, Nippon Medical School

3. Department of International Community Health, Graduate School of Medicine, University of Tokyo

4. Disaster Assistance Division, Japan International Cooperative Agency (JICA) 